\title{
Demographic Characteristics and its Impact on Health Policy in Japan
}

\author{
Shinya Matsuda \\ Department of Preventive Medicine and Community Health, School of Medicine, \\ University of Occupational and Environmental Health
}

\begin{abstract}
The demographic situation and disease structures are very influential for medical services delivery system and its finance. A rapid ageing is on goimg in Japan. The population of aged more than $65 \mathrm{yr}$ old accounts for $22 \%$ and Total Fertility Rate (TFR) was 1.37 in 2008. The total population is decreasing since 2006. This demographic change means the increase in users of social and health services and the decrease of tax payers, which requires the Japanese government to re-organize its social security system. The mortality has been also dramatically decreased during the past 50 decades. It is considered that this improvement in health status was caused by the following factors; improvement of general hygiene, medical system and nutrition, relatively small incidence of violence, relatively moderate climate and so on. On the other hand, the ageing and westernization of the lifestyle have changed the disease structure from the acute to chronic diseases dominant patterns. For example, diabetes mellitus and mental disorders have become new health threats for the Japanese population. Because of this dramatic change in demography and disease structures, we face to a fundamental problem concerning how to make our social system sustainable.
\end{abstract}

Key words: ageing, health system, social security system, Japan

\section{The Japanese administration system and financial situation}

The Japanese administration system comprises three levels; central government, 47 prefectures, and 1,727 municipalities. Each of the three levels of government has its assembly and chief. For the local governments, inhabitants directly elect both. In the case of central government, the citizens directly elect the members of the Diet, and the Diet members elect the Prime Minister. Central government establishes the principles and basic laws. The Ministry of Health, Labour and Welfare has responsibility for the national health policy. The national health policy is materialised

\footnotetext{
Received: June 2, 2010

Accepted: September 29, 2010

Correspondence: S. Matsuda, Department of Preventive Medicine and Community Health, University of Occupational and Environmental Health, 1-1 Iseigaoka, Yahatanishiku, Kitakyushu, Fukuoka 807-8555, Japan

e-mail: smatsuda@med.uoeh-u.ac.jp
}

through local governments; prefecture and municipality. Most of the basic health and welfare services, such as those for mother and child, the elderly, and the handicapped, are provided under the responsibility of the municipal government. The prefecture co-ordinates activities among the different municipalities and provides direct health services for specific problems, such as tuberculosis, AIDS, and the mentally handicapped.

Because of the instability of political scene, there have been frequent changes of prime minister within the past $20 \mathrm{yr}$. The unstable political situation has made it difficult for the government to establish a long term strategies for the coming aged society. The too strong populism among the politicians has resulted in many unnecessary public investments that were implemented in order to attract the voters in the rural areas. Furthermore, the rivalry among the different ministries has caused many duplications of projects with similar purposes. A series of mistakes done by politicians and their supporters caused a tremendous amount of debt for the government. In 2010, the total 
Table 1 Age structure and its chronological trend in Japan

\begin{tabular}{|c|c|c|c|c|c|c|}
\hline & \multicolumn{2}{|c|}{$0-14$ yr old } & \multicolumn{2}{|c|}{$15-64 \mathrm{yr}$ old } & \multicolumn{2}{|c|}{65 yr old - } \\
\hline & $\begin{array}{l}\text { Population } \\
\text { (thousands) }\end{array}$ & $\%$ & $\begin{array}{l}\text { Population } \\
\text { (thousands) }\end{array}$ & $\%$ & $\begin{array}{l}\text { Population } \\
\text { (thousands) }\end{array}$ & $\%$ \\
\hline 1950 & 29,428 & $35.4 \%$ & 49,658 & $58.8 \%$ & 4,109 & $4.9 \%$ \\
\hline 1960 & 28,067 & $30.0 \%$ & 60,002 & $62.9 \%$ & 5,350 & $5.7 \%$ \\
\hline 1970 & 24,823 & $23.9 \%$ & 71,566 & $66.9 \%$ & 7,331 & $7.1 \%$ \\
\hline 1980 & 27,507 & $23.5 \%$ & 78,835 & $65.0 \%$ & 10,647 & $9.1 \%$ \\
\hline 1990 & 22,486 & $18.2 \%$ & 85,904 & $65.9 \%$ & 14,895 & $12.1 \%$ \\
\hline 2000 & 18,505 & $14.6 \%$ & 86,380 & $66.2 \%$ & 22,041 & $17.4 \%$ \\
\hline 2005 & 17,521 & $13.8 \%$ & 84,092 & $64.8 \%$ & 25,672 & $20.2 \%$ \\
\hline 2008 & 17,176 & $13.5 \%$ & 82,300 & $82.7 \%$ & 28,216 & $22.1 \%$ \\
\hline
\end{tabular}

Source: Ministry of Internal Affairs and Communications, Statistics Bureau: Population Estimates.

Table 2 Chronological change of mortality rate in Japan

\begin{tabular}{|c|c|c|c|c|c|c|}
\hline & \multicolumn{3}{|c|}{$\begin{array}{c}\text { Crude Death Rate } \\
\text { (per } 1,000 \text { population) }\end{array}$} & \multicolumn{2}{|c|}{$\begin{array}{c}\text { Age Adjusted DR } \\
\text { (per } 1,000 \text { population) }\end{array}$} & \multirow[t]{2}{*}{$\begin{array}{c}\text { Infant Mortality } \\
\text { (per } 1,000 \text { live births) }\end{array}$} \\
\hline & Total & Male & Female & Male & Female & \\
\hline 1950 & 10.9 & 11.4 & 10.3 & 18.6 & 14.6 & 60.1 \\
\hline 1960 & 7.6 & 8.2 & 6.9 & 14.8 & 10.4 & 30.7 \\
\hline 1970 & 6.9 & 7.7 & 6.2 & 12.3 & 8.2 & 13.1 \\
\hline 1980 & 6.2 & 6.8 & 5.6 & 9.2 & 5.8 & 7.5 \\
\hline 1990 & 6.7 & 7.4 & 6.0 & 7.5 & 4.2 & 4.6 \\
\hline 2000 & 7.7 & 8.6 & 6.8 & 6.3 & 3.2 & 3.2 \\
\hline 2005 & 8.6 & 9.5 & 7.7 & 5.9 & 3.0 & 2.6 \\
\hline 2008 & 9.1 & 9.9 & 8.3 & NA & NA & 2.6 \\
\hline
\end{tabular}

Source: MHLW: 2008 Vital Statistics.

amount of debt is estimated for 860,000 billion yen ${ }^{1)}$. Every years one third of total budget is prepared for the payment for the interest of national bond. This figure is the worst among the OECD countries.

\section{Demography2)}

According to the official statistics on 1st October 2008, the Japanese total population was 12.8 million, of which $48.8 \%$ were male and $51.2 \%$ were female. Compared with 2007 statistics, the total population has decreased by $79,000(-0.06 \%)^{2}$.

Table 1 shows the age structure in 2008 with chronological change ${ }^{2)}$. As shown in the table, the population ageing is on going. According to the projection by the National Institute of Population and Social Security Research, the population over $65 \mathrm{yr}$ old will be $30.5 \%$ in $2025^{3)}$. The most important factor associated with this rapid graying is decreased Total Fertility Rate (TFR). The TFR has been decreasing from 1.75 in 1990 to 1.37 in 2008. Increasing age of marriage and the first birth among female population, increase of un-married population are principal factors behind this phenomenon.

Along with the graying of society, the number of so-called "aged household" is increasing. The "aged household" corresponds to the household with single aged or that with aged couple. Among the households with the aged over $65 \mathrm{yr}$ old, the percentage of single aged household has increased from $8.6 \%$ in 1975 to $22.0 \%$ in 2008 , and aged couple household has also increased from $13.1 \%$ in 1975 to $29.7 \%$ in $2008^{4}$. This situation requires the socialization of care for the frail aged. This fact is one of the most important reasons for the introduction of Long Term Care Insurance (LTCI) scheme in 20005). 


\section{Health statistics}

As shown in Table 2, the health status of Japanese has been dramatically improved after the World War $\mathrm{II}^{6}$. Today, Japan is ranked one of the healthiest countries around the world. Improvement of general hygiene, medical system and nutrition, relatively small incidence of violence and fatal accident, and relatively moderate climate are considered as contributed factors for this improvement.

Table 3 shows the causes of death with the time trends ${ }^{6}$. Along with the economic development, the Japanese disease structure has changed from the acute diseases dominant to chronic diseases dominant pattern. Today the three major causes of death (cancer, heart diseases, and cerebro-vascular diseases) account for $60 \%$ of total deaths.

Table 4 shows the cancer mortality stratified by sex and site with its chronological changes ${ }^{6}$. Remarkable increases are observed for colon, liver, pancreas, lung for both sex, and breast for female, while the number of death by stomach cancer has been relatively stable, and the number of death by uterine cancer has decreased. It is thought that the change in diet habit from the traditional Japanese to the Occidental pattern might contribute to the increase in colon cancer and on the contrary to decrease of stomach cancer.

Among the developed countries, Japan is categorized into one of the highest prevalence rate of smoking. This fact may explain a recent rapid increase of lung cancer cases. For liver cancers, the viral hepatitis (B and C) is the most important risk factor. After the introduction of comprehensive program against viral hepatitis, including screening and vaccination program for pregnant women and born children in order prevent the vertical infection, the number of death by the liver cancer will decrease in future. The introduction of systematic screening program by PAP test is one of the most important factors of decreasing in mortality by uterine cancer. The public supported screening program is available for women over $30 \mathrm{yr}$ old at the contracted obstetric and gynecological clinics. However, the umber of uterine cancer cases among females under $30 \mathrm{yr}$ is increasing recently. The expansion of HPV (Human Papilloma Virus) infection among the young generation is thought as one of the possible reasons. Thus, the government is planning to expand the uterine cancer screening program for younger ages.
Table 3 Chronological change of the causes of death in Japan (per 100,000 persons)

\begin{tabular}{|c|c|c|}
\hline & \multicolumn{2}{|l|}{1950} \\
\hline & Pathology & Death Rate \\
\hline $1 \mathrm{st}$ & Tuberculosis & 146.4 \\
\hline 2 nd & CerebroVascular Diseases & 127.1 \\
\hline $3 r d$ & Pneumonia & 93.1 \\
\hline 4th & Gastro-enteritis & 82.4 \\
\hline 5 th & Cancer & 77.4 \\
\hline 6 th & Senile death & 70.2 \\
\hline 7 th & Heart diseases & 64.2 \\
\hline 8 th & Diseases of Nenate & 62.2 \\
\hline 9th & Accident & 39.5 \\
\hline \multirow[t]{3}{*}{ 10th } & Nephritis and Nephrosis & 32.4 \\
\hline & \multicolumn{2}{|l|}{1970} \\
\hline & Pathology & Death Rate \\
\hline $1 \mathrm{st}$ & CerebroVascular Diseases & 175.8 \\
\hline 2nd & Cancer & 116.3 \\
\hline $3 \mathrm{rd}$ & Heart diseases & 86.7 \\
\hline 4th & Accident & 42.5 \\
\hline 5 th & Senile death & 38.1 \\
\hline 6 th & Pneumonia & 34.1 \\
\hline 7 th & Hypertensive diseases & 17.7 \\
\hline 8 th & Tuberculosis & 15.4 \\
\hline 9th & Suicide & 15.3 \\
\hline \multirow[t]{3}{*}{ 10th } & Liver cirhosis & 12.5 \\
\hline & \multicolumn{2}{|l|}{2008} \\
\hline & Pathology & Death Rate \\
\hline $1 \mathrm{st}$ & Cancer & 272.2 \\
\hline 2 nd & Heart diseases & 144.4 \\
\hline $3 r d$ & CerebroVascular Diseases & 100.8 \\
\hline 4th & Pneumonia & 91.5 \\
\hline 5 th & Accident & 30.2 \\
\hline 6 th & Senile death & 28.5 \\
\hline 7 th & Suicide & 24.0 \\
\hline 8th & Renal failure & 17.9 \\
\hline 9th & Liver diseases & 12.9 \\
\hline 10th & COPD & 12.3 \\
\hline
\end{tabular}

Source: MHLW.

At the moment, the public supported cancer screening program is available for lung, stomach, colon, liver, uterus, and breast, although some of them are criticized about the effectiveness. Furthermore, the low utilization rate of cancer screening is another important problem for the Japanese health policy. For example, the rates of 2007 were $32.5 \%, 27.5 \%$, for stomach and colon (male), and 25.3\%, 22.7\%, 20.3\% 
Table 4 Number of cancer death stratified by organ

\begin{tabular}{lrrrr}
\hline & 1970 & 1980 & 2000 & 2007 \\
\hline Male & & & & \\
Total cancer & 67,074 & 93,501 & 179,140 & 202,743 \\
Stomach & 29,653 & 30,845 & 32,798 & 33,143 \\
Colon & 4,303 & 7,724 & 19,868 & 22,846 \\
Liver & 5,868 & 9,741 & 23,602 & 22,300 \\
Pancreas & 2,549 & 4,483 & 10,380 & 13,029 \\
Lung & 7,502 & 15,438 & 39,053 & 47,685 \\
Others & 17,199 & 25,270 & 53,439 & 63,740 \\
\hline Female & & & & \\
Total cancer & 52,903 & 68,263 & 116,344 & 133,725 \\
Stomach & 19,170 & 19,598 & 17,852 & 17,454 \\
Colon & 4,196 & 7,015 & 16,080 & 11,323 \\
Liver & 3,574 & 4,227 & 10,379 & 11,299 \\
Pancreas & 1,850 & 3,352 & 8,714 & 11,605 \\
Lung & 2,987 & 5,856 & 14,671 & 17,923 \\
Breast & 2,486 & 4,141 & 9,171 & 11,323 \\
Uterus & 6,573 & 5,465 & 5,202 & 5,622 \\
Others & 12,067 & 18,609 & 34,275 & 47,176 \\
\hline
\end{tabular}

Source: MHLW.

and $21.3 \%$ for stomach, colon, breast and cervical cancer (female), even though the effectiveness of screening for these cancers have been scientifically clarified $^{7)}$. It is very important to recognize that average life years lost was very large for these cancers. Pham et al. estimated that $25.2 \mathrm{yr}$ both for breast and uterine cancers, 15.5 and $15.4 \mathrm{yr}$ for stomach and colon cancers, respectively ${ }^{8}$. Both local and central government are making their effort to increase the utilization rate; i.e., distribution of free ticket for cancer screening, cancer screening program for weekend and holidays, PR activities via mass medias. However, it does not seem that these activities have caused much influence on the citizen's behavior. It is necessary to re-consider the strategy of anti-cancer program from the view point of social marketing.

The Japanese Ministry of Health, Welfare and Labor conducts the Patient survey every 3 yr. The MHLW estimates utilization rate (UR) as a morbidity data using the results of this survey. Table 5 shows the URs stratified by diseases, out- and in-patient, and sex in $2005^{9)}$. For in-patient, the highest UR is observed for mental and behavioral disorder (255 per 100,000 persons), followed by the disorder of circulatory system (249). For out-patient, the disorders of digestive system showed the highest UR (1019), and then disor- ders of circulatory system (743).

\section{Medical expenditures ${ }^{10}$}

\section{Definition}

The national health expenditures (NHEs) are the expenditures that the people spend for the treatment of injuries or diseases at medical institutions and other facilities in a year. The expenditure is calculated on the basis of the expenditure of public medical insurance rather than that of medical institutions. It is very important to recognize that there are differences in the definition of national health expenditures among the countries. In the case of Japan, NHEs include medical fees, patient co-payments, the supply of medicines, nursing expenditures, patient transport expenditures and some others, but do not include the expenditures of normal childbirth, expenditures needed for health examination for the maintenance and improvement of health, expenditures of pay beds, part of the construction costs of public medical institutions and some other expenditures. Also, because health expenditures is exempt from consumption tax in principle, the national health expenditures does not include taxes levied on expenditures either. 
Table 5 Utilization rate of medical services stratified by age category, in- and out-patient services, and disease categories (2005, per 100,000 populations)

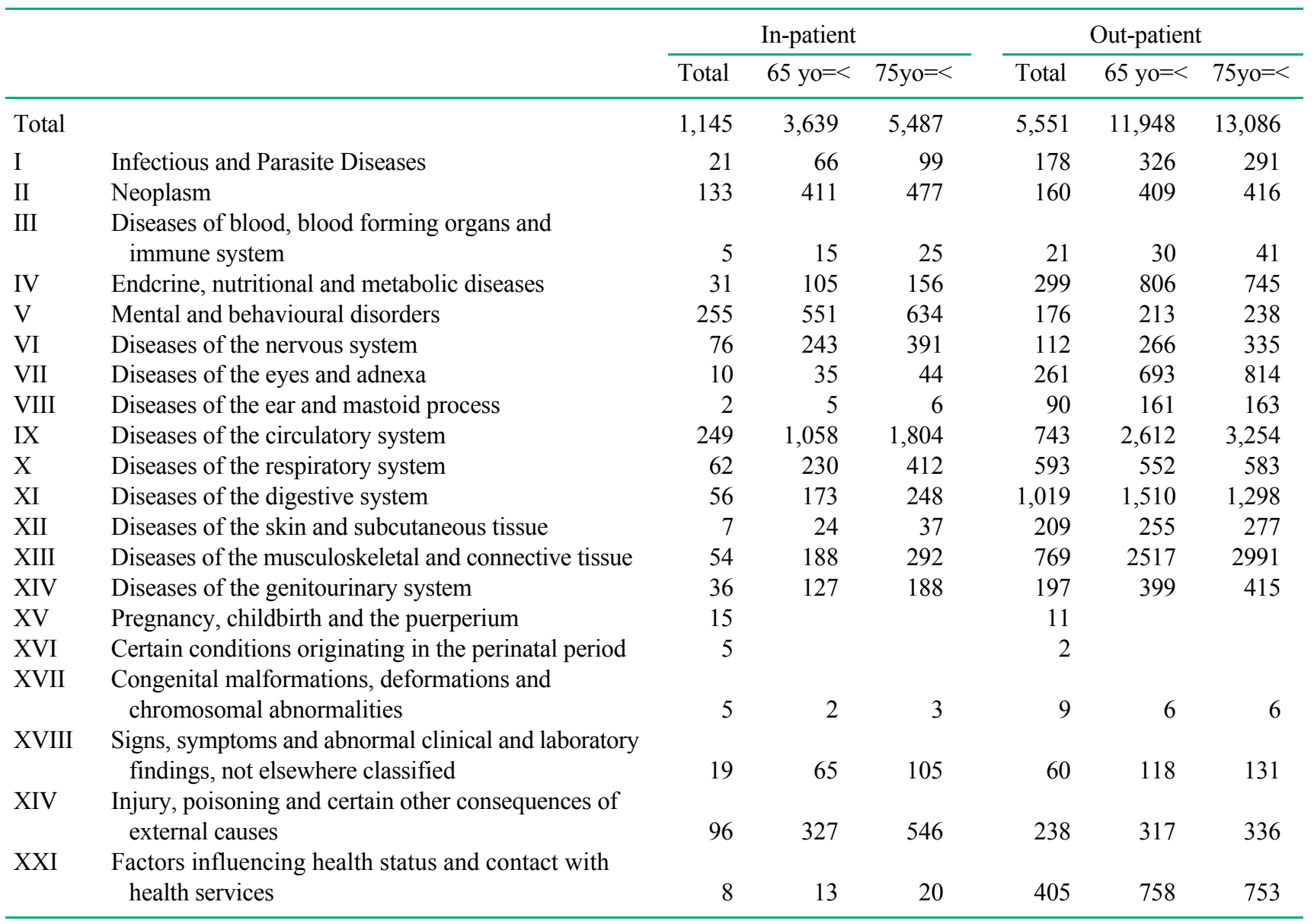

Source: MHLW: Patient Survey 2005.

\section{Time trend}

The national health expenditures in Japan are increasing. In 2006, the expenditures totaled to $¥ 33,127.6$ billion and were $¥ 259,300$ per person. This figure corresponds to $8.9 \%$ of National Income (NI). Compared with other OECD countries, this rate is relatively low. However, the annual increase of 1,000 billion yen is considered as a financial burden under the current low economic growth. Although Japan adopts the social insurance scheme, about $36.6 \%$ of total cost is financed by the general tax. This is why the Ministry of Finance strongly wishes to control the increase of medical expenditures.

\section{Structure of THE}

The breakdown of the national health expenditures in Japan in 2006 is as follows: according to the type of medical services, general health expenditures of hospitalization make up $37.0 \%$, general health expenditures of outpatients - $38.6 \%$, dental clinics $-7.6 \%$, pharmacies $-14.2 \%$, expenditures of meal services for inpatients $-2.5 \%$ and expenditures of home-visit nursing care for the elderly $-0.1 \%$.

In 2006, the health expenditure of the elderly aged 65 or over (hereinafter referred to as "health expenditure of the elderly”) reached $¥ 17,123.3$ billion. Health expenditures of the elderly are rapidly increasing and account for as high as about $51.7 \%$ of the national health expenditures.

\section{Factors contributing to increase in THE}

The structural analysis of increase rates of the national health expenditures during 2000 and 2003 showed that among the total growth rate of $0.7 \%$, $1.8 \%$ were population increase and aging (change in the population structure by age cohort), $-3.5 \%$ were revision of tariff schedule and health system, and $2.2 \%$ were natural increase including the effect of 
advance in medical technology ${ }^{11)}$. This result suggested a large impact of aging and advance of medical technology on increase of THE.

Per capital expenditures are obtained by the following equation:

\section{Per capita health expenditures \\ $=$ medical care receiving rate \\ $\times$ number of days per medical care \\ $\times$ health expenditures per day}

The reasons of high health expenditures of the elderly is contributed to the high medical care receiving rate, which is the indicator showing the frequency per a given period (per month) of visits to medical institutions (number of medical care received) by participants in medical insurance. In 2006 the medical care receiving rate of the elderly is 6.5 times more than that of young people in hospitalization and 2.5 times in outpatient care. The elderly people suffer from multiple chronic diseases, such as diabetes and hypertension, thus it is very natural that they visit medical institutions more often. The Japanese medical system permits for patients the free access without any gate keeping. It is considered that this characteristic contributes to the high consultation rate of elderly patients.

Some of the previous literatures denied the direct effect of ageing on the increase in health care expenditures ${ }^{12,13)}$. They indicated that the advance in medical technology is the most important factor for the increase in medical expenditures.

The increase of aged population means the increase of patients who need medical care. Along with the ageing of the society, the number of patients with cancer, cardio-vascular diseases and other lifestyle related diseases has been increasing. The recent advance in medical technology has made it possible to save the lives of acute patients, such as acute myocardial infarction and stroke patients. As a result, such patients require acute medical care services and then following chronic care services. This situation naturally expands medical expenditures. In this meaning, the advance in medical technology is the most important factor for the increase in health care expenditures, as indicated by $\mathrm{Yu}^{13)}$. However, it seems difficult to clearly separate the effect of technology advance and that of ageing.

After 2015, the post-war baby boomer's generation will enter their old aged generation (that is over 75 yr old). Considering the further graying of the Japanese society with structural changes in disease structure (i.e., more chronic diseases) and advance of medical technology, it is an urgent task for the government to re-organize the health system and the related social systems.

\section{* Conclusion}

Because of the dramatic change in demography and disease structures, we face to a fundamental problem on how to reconstruct our social system. It is an emergent challenge how to reform the social security system in order to make it sustainable. The most important premise is to maintain the social security services for the entire population. As the Japanese social security system adopt a transposition system from young to old generation, the current demographic change makes the system very vulnerable.

Actually, the number of citizens who do not want pay their premium for pension is increasing. They may justify their behavior in saying that they cannot expect enough return in future and that they prefer a private pension scheme. This is a fundamental problem for the philosophy of social security system in Japan, where the solidarity has long been considered as the base principle. For the past decades, the government has implemented a series of fragmented countermeasures in order to make the social security scheme sustainable for a short term. Unfortunately they have not explained enough about the philosophy of social security.

Concerning policy on the health reform, there is a tough discussion between the Neo-liberalist and the Socio-democrat. The Neo-liberalist groups ask a more market oriented reform such as de-regulation of health market. For example, the permission of private insurance company for the current public health insurance system with the scheme of managed care, liberalization of price setting of health services with the permission of private company managed hospitals are some of their opinions. On the contrary, the sociodemocratic groups such as the Japan Medical Association and labor unions recommend further contribution of government. The increase of consumption tax as a resource of social security system is an example of their opinions. The $1 \%$ of increase in consumption tax will mean 100 billion of tax income increase. However, the current cabinet is very reluctant to the 
increase because of fear for losing in the coming election.

At the moment, there is no final conclusion about this debate. However, the population change is an assured future. We have to prepare it. In order to facilitate the discussion, the Japanese government tries to implement a standardized infrastructure of health information. For example, the Diagnosis Procedure Combination (DPC) based data is available from 2002. Using this kind of data, we have to establish the information based or evidence based negotiation system in stead of the current vicious corporatism decision making system. It is the time to start concrete actions for future.

\section{References}

1) Ministry of Finance: Japanese Public Finance Fact Sheet -FY2010 Budget (Supplementary Data)-, http://www.mof.go.jp/english/budget/ pamphletjpffs2010s.pdf (access 23 August 2010).

2) Ministry of Internal Affairs and Communications, Statistics Bureau: Current population estimates as of October 1, 2008, http://www.stat.go.jp/english/data/ jinsui/2008np/index.htm (access 23 March 2010).

3) National Institute of Population and Social Security Research: Population Statistics of Japan 2008, http:// www.ipss.go.jp/p-info/e/psj2008/PSJ2008.pdf (access 23 August 2010).

4) Ministry of Health, Labour and Welfare: Comprehensive survey on living conditions of the people on health and welfare 2008, http://www.mhlw.go.jp/ toukei/saikin/hw/k-tyosa/k-tyosa08/index.html (access 23 March 2010).

5) Matsuda S: Health Insurance Scheme for the Aged in Japan - its outline and challenges-. APJDM 3, 1-9 (2009).

6) Ministry of Health, Labour and Welfare: 2008 Vital Statistics, http://www.e-stat.go.jp/SG1/estat/ GL08020101.do?_toGL08020101\&tstatCode= $000001028897 \&$ requestSender $=$ dsearch (access 23 August 2010).

7) Cancer Research Institute: http://ganjoho.jp/public/ statistics/pub/kenshin.html (access 23 March 2010).

8) Pham TM, Fujino Y, Matsuda S, Yoshimura T: Premature mortality due to cancer in Japan, 1995 and 2005. International Journal of Cancer 127, 190-194 (2010).

9) Ministry of Health, Labour and Welfare: Patient Survey 2005, http://www.mhlw.go.jp/toukei/saikin/ hw/kanja/05syoubyo/index.html (access 23 March 2010).

10) Ministry of Health, Labour and Welfare: Estimates of National Medical Care Expenditure, http:// www.mhlw.go.jp/toukei/saikin/hw/k-iryohi/06/ toukei1.html (access 23 March 2010).

11) Ohshima K: Application of IT for health reform in Japan, http://www.jahis.jp/it-board/h19-sympo/ H19sympo_pre/03-1\%E3\%80\%80oshima.pdf (access 23 March 2010).

12) Lubitz J, Liming $C$, Kramarow E, Lentzner $H$ : Health, Life expectancy, and health care spending among the elderly. NEJM 349, 1048-1055 (2003).

13) Yoo BK: Health Economics for "Reform". Osaka: MC Medica Shuppan, 2006 (in Japanese). 